\title{
FANTM: THE FIRST ARTICLE NIF TEST MODULE FOR THE LASER POWER CONDITIONING SYSTEM*
}

\author{
David L. Smith, J. Michael Wilson ${ }^{+}$, Henry C. Harjes, and William B. S. Moore \\ Sandia National Laboratories ${ }^{\#}$ \\ P. O. Box 5800, Albuquerque, NM 87185-1184
}

\author{
Jud Hammon \\ Maxwell Physics International \\ 2700 Merced St., San Leandro, CA 94577
}

\section{Abstract}

Designing and developing the 1.7 to $2.1-\mathrm{MJ}$ Power Conditioning System (PCS) that powers the flashlamps for the National Ignition Facility (NIF), currently being constructed at Lawrence Livermore National Labs (LLNL), is one of several responsibilities assumed by Sandia National Labs (SNL) in support of the NIF Project. The test facility that has evolved over the last three years to satisfy the project requirements is called FANTM. It was built at SNL and has operated for about 17,000 shots to demonstrate component performance expectations over the lifetime of NIF. A few modules similar to the one shown in Fig. 1 will be used initially in the amplifier test phase of the project. The final full NIF system will require 192 of them (48 in each of four capacitor bays).

This paper briefly summarizes the final design of the FANTM facility and compares its performance with the predictions of circuit simulations for both normal operation and fault-mode response. Applying both the measured and modeled power pulse waveforms as input to a physics-based, semi-empirical amplifier gain code indicates that the 20-capacitor PCS can satisfy the NIF requirement for an average gain coefficient of $5.00 \% / \mathrm{cm}$ and can exceed $5.20 \% / \mathrm{cm}$ with 24 capacitors.

\section{FANTM PULSED POWER DESIGN}

The FANTM bank consists of 20 (24 max) $86-\mathrm{kJ}$, nominally $300-\mu \mathrm{F}$ capacitors that are operated in parallel near $24 \mathrm{kV}$. Each capacitor is isolated from the rest of the bank by the current-limiting damping elements, which are $25-\mathrm{m} \Omega, 9-\mu \mathrm{H}$ resistive coils. They connect to a single bus that feeds the gas switch. The single ST300A airinsulated switch transfers over 500-kA peak current in a

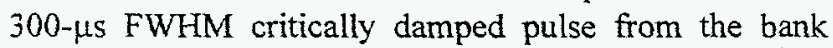

\footnotetext{
* The US DOE under Contract No. W-7405-ENG-48 supported this work.

+ Presently at Lawrence Livermore National Laboratories, Livermore, CA.

"Sandia is a multi-program laboratory operated by Sandia Corporation, a Lockheed Martin Company, for the US DOE under Contract DE-AC04-94AL85000.
}

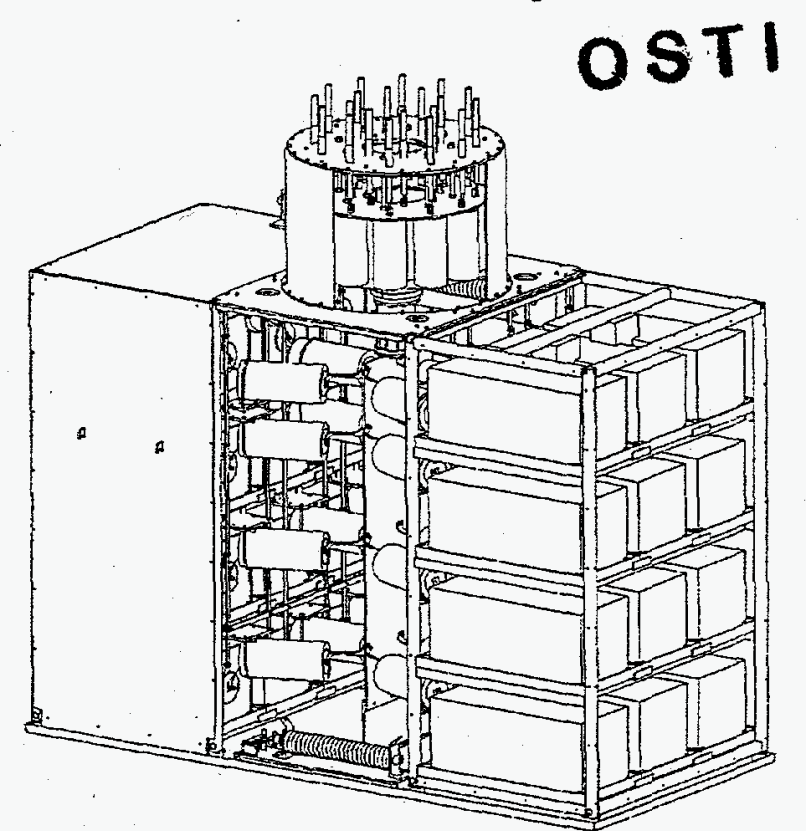

Figure 1. View of uncovered 24 capacitor PCS module.

into 20 parallel output lines. Each of these lines is composed of a matched ballast inductor, an RG 220/U coaxial cable, which is $47.6-\mathrm{m}$ long, and either a dummy resistive load or a pair of series-connected flashlamps. The full NIF will also include modules with a range of output cable lengths from 20 to $55 \mathrm{~m}$, due to the different locations of the PCS modules with respect to the laser amplifiers. The main bank module has a weight of approximately 7 metric tons, a footprint of about 1.52 by $3.35 \mathrm{~m}$, and a total height of about $3.11 \mathrm{~m}$. A flashlamp pre-ionization pulse from a smaller $50-\mathrm{kJ}$ PreIonization/Lamp Check (PILC) parallel bank precedes the main pulse by a few hundred microseconds. The following subsections describe the PCS components in more detail.

\section{A. High Energy Density Capacitors}

The metallized-dielectric, self-healing capacitors which are supplied by several sources are installed in two facing columns, or racks, each three capacitors wide and four high. The opening in the frame for each capacitor is $50.8 \times 50.8 \times 101.6 \mathrm{~cm}$, sufficient to allow about $5-\mathrm{cm}$ 


\section{DISCLAIMER}

This report was prepared as an account of work sponsored by an agency of the United States Government. Neither the United States Government nor any agency thereof, nor any of their employees, make any warranty, express or implied, or assumes any legal liability or responsibility for the accuracy, completeness, or usefulness of any information, apparatus, product, or process disclosed, or represents that its use would not infringe privately owned rights. Reference herein to any specific commercial product, process, or service by trade name, trademark, manufacturer, or otherwise does not necessarily constitute or imply its endorsement, recommendation, or favoring by the United States Government or any agency thereof. The views and opinions of authors expressed herein do not necessarily state or reflect those of the United States Government or any agency thereof. 


\section{DISCLAIMER}

Portions of this document may be illegible in electronic image products. Images are produced from the best available original document. 
expansion in each dimension without hindering removal. The capacitors are insulated from the module frame by PVC trays, $0.32-\mathrm{cm}$ thick, with a $5.7-\mathrm{cm}$ lip. The nominal NIF bank is charged in approximately $60 \mathrm{~s}$. Designing capacitors with an equivalent series resistance of $<20 \mathrm{~m} \Omega$ was an additional challenge for the vendors. The capacitor banks are electrically floating inside a $1-\mathrm{cm}$ thick steel enclosure, which is connected to facility ground. This protects personnel from direct exposure to the hazardous voltages. The enclosure and vented side panels serve the additional purpose of debris containment for the rare occasions when the large stored energy finds an alternative fault path to ground.

\section{B. Damping Elements}

Stainless steel coils with a mean diameter of $11.6 \mathrm{~cm}$ and a wire diameter of $1.43 \mathrm{~cm}$ serve to protect the capacitors from the rest of the bank for the case of an internal capacitor fault. These are covered by fiber cloth and epoxy reaching about $19.4 \mathrm{~cm}$ in diameter and 42.1 $\mathrm{cm}$ in length. The damping elements are sufficiently robust to maintain mechanical integrity after a major fault (up to $390 \mathrm{kA}$ ), although they would not be able to continue operating after that. They attach to the capacitor center conductor and the switch bus with $0.32-\mathrm{cm}$ thick copper straps.

\section{High Voltage Bus and Dump Resistors}

The vertical bus is a $59.7-\mathrm{cm}$ wide plate of $1.27-\mathrm{cm}$ thick aluminum that tapers near the top to bolt to the lower switch plate. It is supported from the floor by two $1.27-\mathrm{cm} \mathrm{G-10}$ plates. It is connected to the main bank power supply through a charge-isolation circuit. We added shelves to the bus to support the damping elements and dump resistors. The PCS module includes two independent safety dump assemblies; one is at the top and the other is at the bottom on the opposite side of the bus. Each assembly is composed of two series stacks of eight, $15.2-\mathrm{cm}$ diameter, $2.54-\mathrm{cm}$ thick carbon composition discs from HVR Advanced Components. Each stack is $540 \Omega$ with a decay time constant of about $3.4 \mathrm{~s}$. A series connected Ross relay, with solenoids requiring ac voltage to open and spring drives for normal closing, is used to provide the fail-safe closure.

\section{Output Switch}

The output switch in Fig. 2 is a Maxwell PI ST-300A spark gap. It has a steel housing and 7-cm diameter pocographite electrodes with an initial gap of $0.32 \mathrm{~cm}$. The switch dielectric medium is dry air, which flows through 5 -micron filters. Extensive testing has resulted in a wellknown self-break curve and very reliable operation at 40 to $50 \%$ of self-break. The air pressure is adjusted according to the predictable gap spacing as the electrodes erode due to the large $145-C$ charge transfer per shot. The switch end-of-life, as determined by reliable triggering range, occurs near 2,000 shots when the gap has grown to about $2.5 \mathrm{~cm}$, for a total transfer of about $300 \mathrm{kC}$. The switch maintenance and refurbishment is simple.

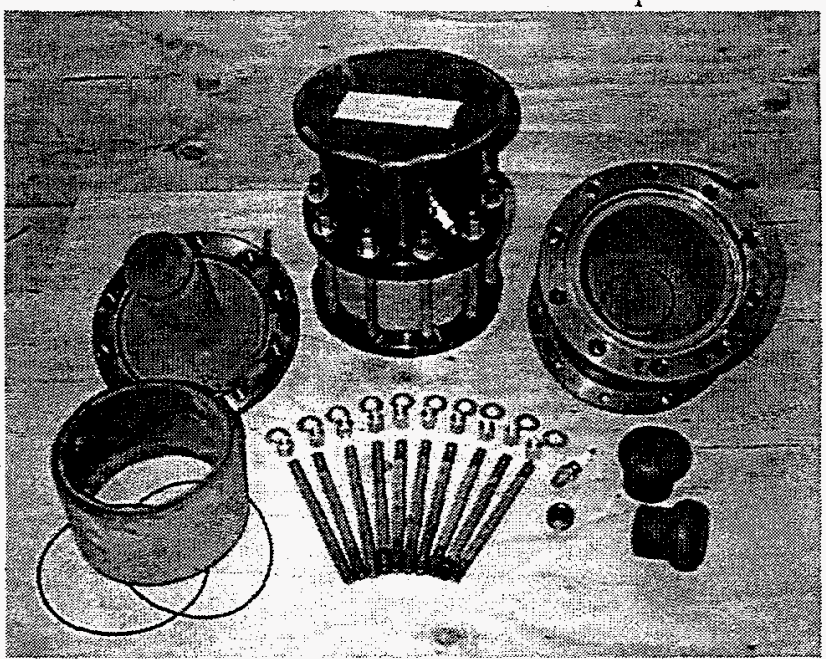

Figure 2. Assembled and disassembled main gas switches.

\section{E. Trigger Generator}

The trigger generator for the PCS output switch is a Maxwell PI TG-803-1, which was developed for this application. It uses an SCR for its main switch, pulsecharging an output capacitor through a pulse-transformer to approximately $95 \mathrm{kV}$. This capacitor is discharged through a sealed gas-filled spark-gap switch and an output blocking capacitor. The generator has a footprint of about $20.3 \times 40.6 \mathrm{~cm}$ and is mounted on top of the module enclosure. Its high voltage bushing passes through a hole in the top plate. The trigger generator output has a Pulsed Power Components' high-curtent fuse connected in series before it enters the side of the module output switch via an automotive spark plug.

\section{F. Trigger Isolation Cores}

The series-injection-trigger for the ST-300 switch requires at least $6 \mu \mathrm{H}$ of inductance between the switch and the low-impedance load, to support the necessary trigger voltage. In FANTM this isolation is provided by a single Ceramic Magnetics' ferrite core, that is about 10.2$\mathrm{cm}$ thick and has inner and outer diameters of 10.2 and $25.4 \mathrm{~cm}$, respectively. It is split into half-rings that are held together by a plastic straps.

\section{G. Ballast Inductors}

The set of 20 ballast inductors is attached to a common $1.27-\mathrm{cm}$ thick aluminum plate, which is fed by the output switch through the isolation cores. Copper coils with a mean diameter of $8.87 \mathrm{~cm}$ and a wire diameter of $0.65 \mathrm{~cm}$ are contained in a fiberglass-reinforced plastic. Fault currents of 100 to $190 \mathrm{kA}$ represent worst-case conditions that the inductors are designed to survive mechanically. 
The assembly is enclosed by a $1.07-\mathrm{m}$ diameter, top-hat shaped housing on top of the PCS module.

The ballast inductors serve the dual purposes of balancing the currents delivered to each output cable and load for a given module, plus matching the pulse shapes for all of the NIF modules with various cable lengths. Most modules will have only one associated cable length, and thus only one value for the set of ballast inductors. However, 24 modules will have two inductor values, due to the use of two different cable lengths to two different amplifiers that they are driving. The NIF module design calls for $<30 \mu \mathrm{H}$ of total inductance for the combination of the ballast inductor, cable, flashlamps, and all the transitions and connections. Four different inductance values will be used to compensate for the different inductances associated with four different ranges of cable lengths as shown in Table 1.

Table 1. NIF ballast inductor single-pitch design.

\begin{tabular}{|c|c|c|}
\hline Inductance $(\mu \mathrm{H})$ & No. Turns & Cable Range(m) \\
\hline 19.1 & 25.5 & $19.8-27.7$ \\
\hline 17.5 & 23.5 & $27.7-38.1$ \\
\hline 14.3 & 19.5 & $38.1-48.2$ \\
\hline 12.8 & 17.5 & $48.2-54.9$ \\
\hline
\end{tabular}

\section{H. Output Cables}

Each module will drive a set of 20 RG-220 coaxial cables, one for each of 20 flashlamp pairs. The round-trip resistance of the cables represents a significant circuit parameter. Hence, a double-shield braid outer conductor configuration will be used for cables shorter than about 38 $\mathrm{m}$, and a triple-shield braid outer conductor configuration will be used for cables longer than $38 \mathrm{~m}$. This compensates somewhat for the higher resistance of the longest cables. On FANTM most of our testing has been with triple-braid cables that were $47.5 \mathrm{~m}$ long. We also plan to reinforce the outer conductors with a fiber-backed mylar tape to ensure the NIF cables will survive lamp faults of $100+\mathrm{kA}$ with no damage or degradation.

Since the modules with the longest cables probably cannot meet the NIF gain requirements when operating at the same charge voltage as the shorter systems, it was decided to allow for voltage adjustments on every module to achieve the best matching of performance. The gain improvement can be accomplished also through handselection of higher-capacitance cans for the higher loss modules, or just by adding a capacitor to the baseline bank of 20 .

\section{Resistor Dummy Loads}

The dummy load assembly consisted of 20 independent floating resistor stacks. The $2-\mu \mathrm{H}$ stacks were composed of five carbon composition discs from HVR Advanced Components that produced an average of $412 \mathrm{~m} \Omega \pm 4 \%$ per stack, about $14 \%$ lower than the expected lamp operating resistance. They were air-cooled with large blower units to maintain a steady operating temperature. The loads performed well, but toward the end of their 7,200 shot series, the interface contacts were degrading, and several stacks had to be replaced.

\section{J. NIF Flashlamp Loads}

The FANTM facility includes 40 flashlamps uniquely designed for the NIF application by two vendors. They are housed in an air-cooled aluminum cabinet that roughly simulates the lamp cassette on NIF. The PCS output cables attach to connectors entering the top of the cabinet. The xenon-filled lamps are $1.8 \mathrm{~m}$ long with a diameter of $4.3 \mathrm{~cm}$. Their nominal resistance at peak current and gain times is $476 \mathrm{~m} \Omega \pm 8 \%$. The lamp variations result in significant amplitude and timing spreads.

\section{K. PILC Module}

The PILC bank and associated hardware are in a separate 0.61 by 1.52 by $1.98-\mathrm{m}$ high cabinet adjacent to the PCS module. It is connected through the PCS top-hat assembly with a series isolation resistor and an RG 220 coaxial cable, which should have a double or triple shield braid for fault tolerance. Typically, three parallel, inductively-isolated capacitors are discharged by a single air-insulated switch into the same load path seen by the PCS main bank. The nominal circuit values are $140 \mu \mathrm{F}$ of capacitance driving a net series inductance of approximately $3.2 \mu \mathrm{H}$ with a net series resistance of about $100 \mathrm{~m} \Omega$. Variations of this circuit can be charged from 24 to $28.5 \mathrm{kV}$ to deliver between 500 and $700 \mathrm{~kJ}$ to each flashlamp. Like the main bank module, the PILC module is contained in an EMI enclosure with the pulsed power system electrically floating relative to the enclosure. The enclosure is tied to the facility ground, and the pulsed power ground is connected to the PCS pulsed power ground through the shield of the output coaxial cable.

\section{Facility Grounding}

The flashlamp load for the PCS module is isolated from facility ground, and the return current follows the cable outer conductors back to the main bank. The ground connection for the pulsed power system is at the PCS module where the module enclosure is tied to facility ground only at the top hat location with insulated leads. To minimize the risk to injury to NIF personnel, a lowinductance, effectively coaxial return shall be used to surround the bundles of output cables between the modules and laser bays.

\section{Diagnostics}

The primary diagnostic tool is a current monitor located at the input of each of the twenty cables in the top-hat assembly. The SNL/EG\&G developed monitor is a Rogowski coil which takes advantage of low cost 
printed circuit board technology. These current probes can be used to monitor the primary main and PILC current pulses as well as their triggers, plus ground and lamp reflector fault currents if they occur. The monitors were calibrated in situ using a single conductor to link them all an a certified reference current viewing resistor. A large Rogowski coil was used at the base of the ballast inductor assembly to measure the total current out of the main bank for a reference; this is not planned for the NIF modules.

The FANTM lamp voltage monitor (also not intended for NIF) is a $2000: 10-\Omega$ voltage divider with a $1: 1$ transformer to isolate the building and pulsed power grounds. Designed for this application, they are calibrated in situ on the 20 lamp loads against a certified reference monitor. Both the properly calibrated voltage and current monitors have demonstrated a shot-to-shot consistency of about $\pm 1 \%$.

Our other primary diagnostic is video cameras that can observe the whole FANTM facility to document any offnormal occurrences. Alternatively, they can zoom onto specific spots of interest or meter displays as an aid in operations and troubleshooting.

\section{N. Auto-Sequencing Controls}

The main and PILC bank power supplies, main and PILC switch trigger generators, gas chassis and supply system, and diagnostic system are all monitored and controlled by an embedded control system. An autosequencing process was developed to allow repetitive firing of FANTM every five to six minutes. This allows for adequate switch purging and filling and avoids overheating any of the circuit elements. When the autosequencer detects all systems are ready, it initiates the next charging cycle and trigger pulse. The sequencing includes firing a lamp check PILC pulse only, between shots of the main bank plus PILC.

\section{FANTM PERFORMANCE}

A significant amount of circuit simulations (PSpice at Maxwell PI and SCREAMER[1] at SNL), field stress modeling (ELECTRO from Integrated Engineering Software), and gain code calculations (Bulkmode[2] and GainCalc V1 .0[2] from LLNL) were conducted during the design and operation phase of the FANTM facility. SCREAMER is a fast-running, quick turn-around, userfriendly network code created and used extensively at Sandia for accelerator development. It requires some care in choosing a simplified representation of the system to be modeled. The codes from LLNL generated a timedependent Average Gain Coefficient (AGC) from an input file consisting of the load power pulse, giving us an accurate estimate of the gain performance without having to drive a real amplifier. These tools provided us with redundant checks and guidelines for analyzing the performance data and to better understand any major or subtle deviations from the simulated predictions. Other software that was used extensively included the Lab View Data Viewer and Microsoft Excel.

\section{A. Fixed Resistor Loads}

The overlay of the PILC and main bank current waveforms in Fig. 3 shows the good agreement between the SCREAMER circuit model results and the measured data from FANTM shot \# 4450. The primary difference is where the simulated curve does not damp out as fast for the PILC pulse. The measured waveform with a peak of $577 \mathrm{kA}$ is actually the sum of all the individual cable Rogowski monitors when the main bank charge was 23.8 $\mathrm{kV}$. The large total current Rogowski coil produces a slightly different wave shape because its physical location is such that it also measures the loss current into the discharged PILC circuit during the beginning of the main pulse.

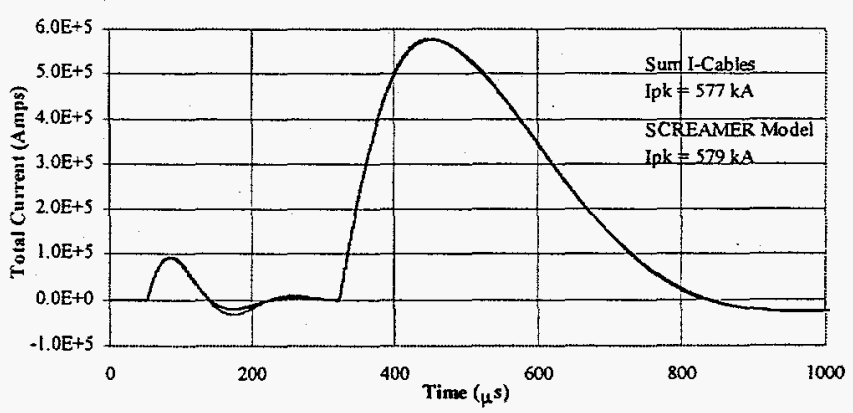

Figure 3. Measured and modeled total currents (\#4450).

The shot-to-shot repeatability of the FANTM pulses satisfied the energy-spread requirements established for NIF. Figure 4 demonstrates the overall variation in peak main bank currents for a 500 shot series with the resistor loads. The horizontal bars represent the $1 \%$-NIF energy spread requirement. Our power supplies showed a tendency to stabilize to a very repeatable charge voltage after about six shots. This temperature sensitivity causes a "first-shot" effect with lower peak values for the initial shot by about $0.5 \%$. Even the larger scatter of the "firstshot" data still fell within the allowed energy window. The different plateaus on the plot correspond to changes in operating conditions, such as the set charge voltage.

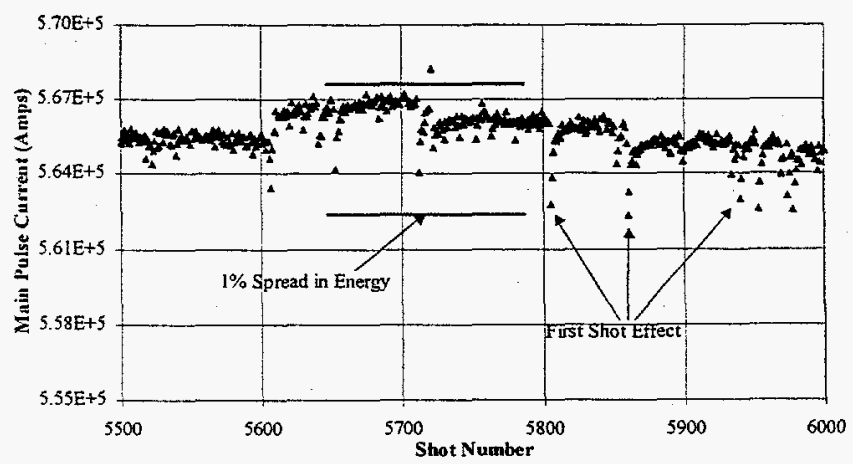

Figure 4. Typical spreads for resistor load current data. 


\section{B. NIF Flashlamp Loads}

The FANTM fixed resistor loads and non-linear flashlamp loads produced significantly different waveforms when driven by the same source. Because of the time-varying impedance of the flashlamps and the geometry of the lamp holder, the shape of the power pulse delivered to the lamp pairs is shorter and broader than that of the resistor load. A comparison of the power waveforms from resistor shot $\# 4450$ and lamp shot $\# 850$ is shown in the overlay of Fig. 5. The lamp loads look more resistive and inductive. It is thus necessary to add inductance-like corrections to the circuit models to achieve good agreement between the simulations and actual data. The best current waveform match occurs when about $12 \mu \mathrm{H}$ is added to each of the modeled flashlamp loads, more than the simple geometry would suggest.

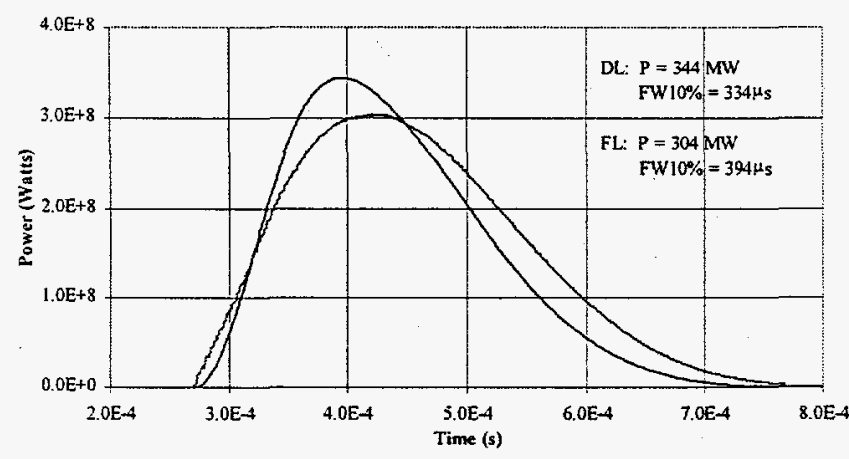

Figure 5. Dummy and flashlamp load power pulses.

Figure 6 shows another total current comparison of a SCREAMER generated waveform and the sum of the cable currents for lamp shot \#850, in which the bank was again charged to $23.8 \mathrm{kV}$. The simulated result is the lower curve for most of the plot. The fit is not quite as good as for the resistor dummy load, but it is sufficient to produce nearly identical gain calculations of 5.03 and $5.04 \% / \mathrm{cm}$ for the model and experiment, respectively.

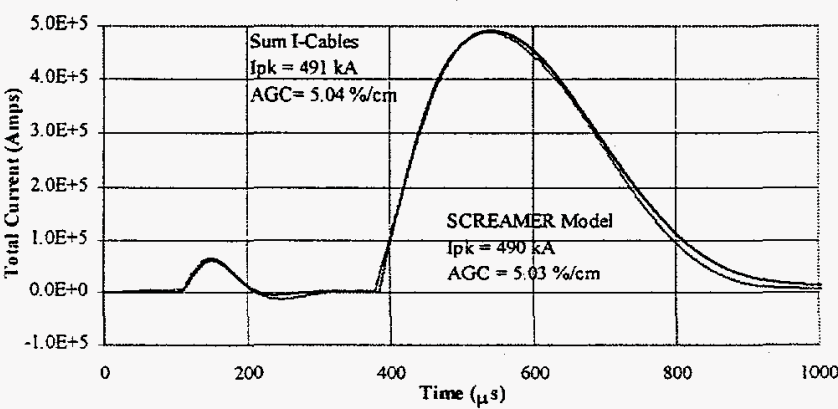

Figure 6. Measured and modeled total currents (L\#850).

The flashlamp load impedance models that we use are approximate I-V relationships derived from breakdown physics, lamp geometry, and experience at LLNL:

$$
\begin{aligned}
& V_{L}=17.6\left(I_{L}\right)^{1 / 2} \\
& V_{L}=78.7\left(I_{L}\right)^{1 / 2} .
\end{aligned}
$$

The Eq. 1 represents 20 series pairs of flashlamps, while Eq. 2 is for a single series pair. The graph of Fig. 7 compares a SCREAMER generated flashlamp load impedance, adjusted in time for the best fit, with a measured load resistance curve based on $R_{L}=V_{L} / I_{L}$ for a single lamp pair (\#15) from lamp shot \#850. The model matches the data best only near the time of peak current. Our resistance model both falls and recovers faster than the measured results indicate for the NIF lamps, which explains the differences between model and experiment. The additional model inductance we required tends to serve as a construct to account for some of the $\mathrm{dR} / \mathrm{dt}$ in the loads.

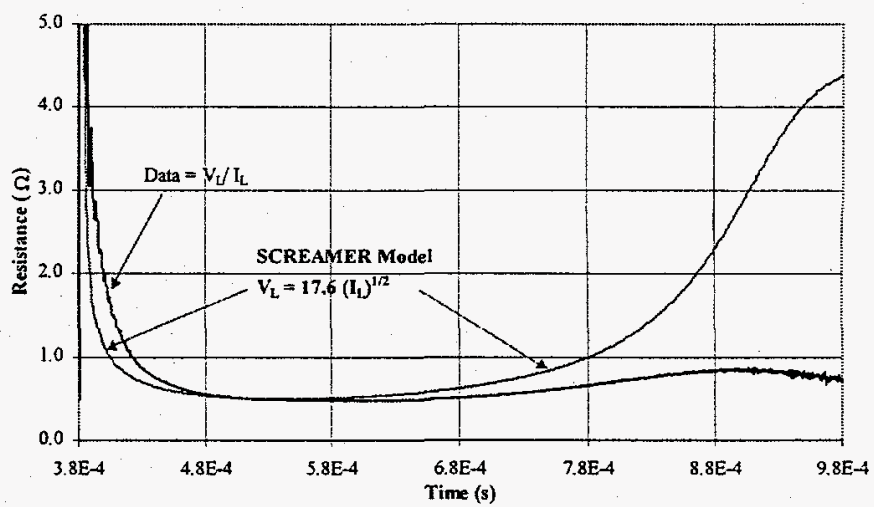

Figure 7. Measured and modeled load resistance (\#850).

The lamp-to-lamp and shot-to-shot uniformity of the main pulse is indicated in Fig. 8. The peak currents seen by three flashlamp pairs are shown representing the highest, average, and lowest of the 20-load assembly over a 1150-shot series. The horizontal bars at the right of the graph show a $3 \%$ spread in energy. The overall lamp-tolamp spread appears to be about $6 \%$, of which $<2 \%$ would be accounted for by variations in the monitor calibrations. The individual lamp load scatter is about $1 \%$. The data points indicated by the "No PILC" label are the result of firing the main bank only. The advantage of the PILC pre-ionization pulse in this case is about $600 \mathrm{~A}$ or $2.5 \%$.

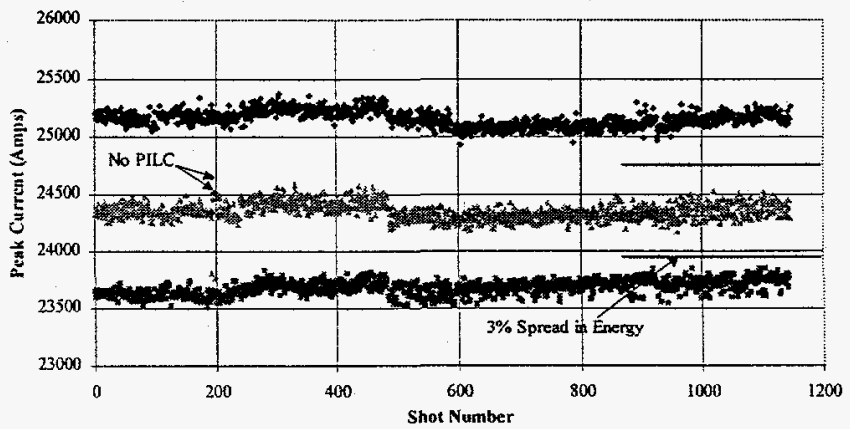

Figure 8. Peak current uniformity for three lamp pairs.

A view of the lamp-to-lamp uniformity within a given shot on FANTM is shown in the bar chart of Fig. 9 for lamp shot \#6153, which happens to be a "first shot" of the day. There is some shot-to-shot jitter of the calculated AGC for each lamp pair, but the relative values of the 
different pairs are quite repeatable. Our investigations have shown that the lamp differences do not appear to depend on location or geometry. The average AGC for all the loads on this shot is $4.99 \% / \mathrm{cm}$, slightly below the desired parameter of $5.00 \% / \mathrm{cm}$ due to a gradual decline in the total bank current toward the end of the testing period.

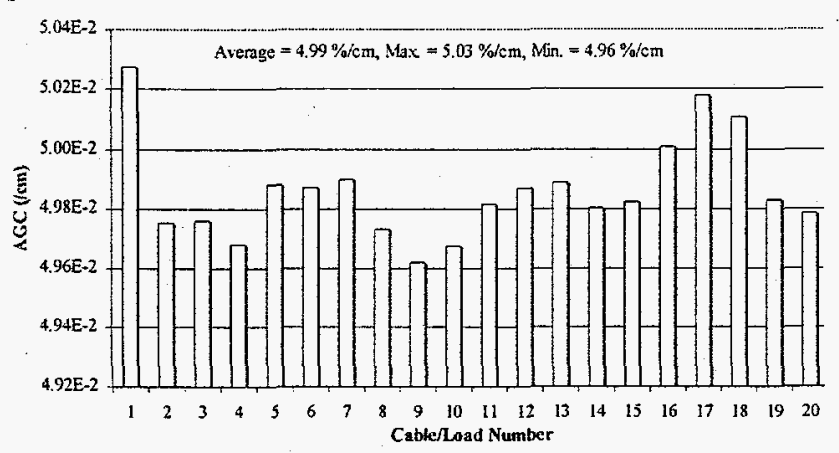

Figure 9. Lamp-to-lamp uniformity for lamp shot \#6153.

The energy delivered to the load depends on charge voltage and bank capacitance, or the number of capacitors. We ran a series of tests on FANTM in which we varied both parameters. Calculating the gain for selected shots and displaying it as in Fig. 10 allows us to identify gain contours and estimated scale factors as an aid for tuning future PCS module/cable/amplifier combinations. The resulting voltage impact on gain goes as $62 \mathrm{~V} / 0.01 \% / \mathrm{cm}$. The scaling for capacitance looks like $1 \mathrm{Cap}(310 \mu \mathrm{F}) / 0.06 \% / \mathrm{cm}$. Both relationships appear close to linear in this small range of variables. The gain contours associated with modules that drive shorter cables should shift left and down with respect to those of Fig. 10.

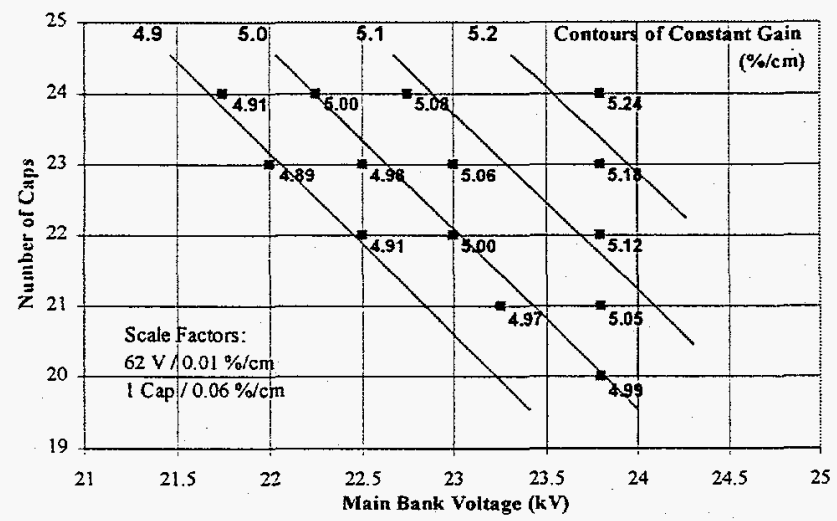

Figure 10. Contours of constant $A G C$ versus $V$ and $C$.

\section{PREDICTED AND MEASURED FAULT CONDITIONS}

A complete summary of our fault analysis and plans is beyond the intent of this section, but some discussion is deemed appropriate. During the course of the FANTM testing, we experienced three major capacitor faults (ranging from 11 to $23.8 \mathrm{kV}$ ), one bus fault through a damaged dump resistor, and one lamp fault. Due to the large number of energized components that will be in NIF, some failures have to be expected, but with the risks minimized and contained. We plan to conduct intentional faults at the end of our test series in which we will more carefully diagnose the fault current and voltage levels. Of particular interest are the possible threats to personnel safety or collateral property damage. Every component on FANTM was considered with respect to the likely and unlikely fault modes that it would be exposed to, or could cause. As an example, the damping elements were designed by considering the trade-off between the loss they cause for normal operation and the maximum fault current they would pass. Figure 11 shows a plot of the normal current and fault current both as a function of the damping element inductance. The bolder line goes with the fault currents on the right-side scale.

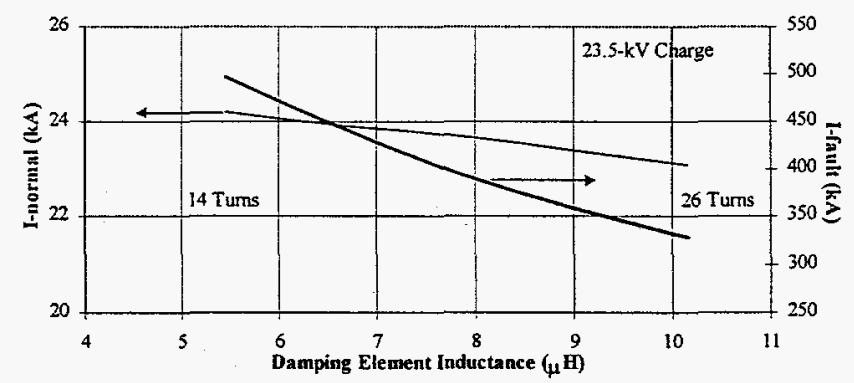

Figure 11. One damping element design trade-off.

An overlay of some of the fault currents our models predict is shown in Fig. 12. The plotted curves represent a bus breakdown to ground, a capacitor internal short, a cable or feed-connector failure at the top-hat assembly, and a lamp failure or Big-Tee connector short near the load. All the curves except the bus fault are associated with the left-side scale, while the bus fault requires the right-side scale. Obviously, the possibility of a bus fault is a failure mode that we want to make statistically remote, because it produces the highest current released and potential for the most damage. The curves of Fig. 12 are generated for specific circuit conditions and assuming a fault-path resistance of 5 to $10 \mathrm{~m} \Omega$. Our experiences with planned faults on another prototype bank have indicated much higher resistances. The actual peak values could vary significantly (e.g. $-50 \%$ to $+10 \%$ ). For instance, our one lamp failure drew a fault current that peaked to about $45 \mathrm{kA}$.

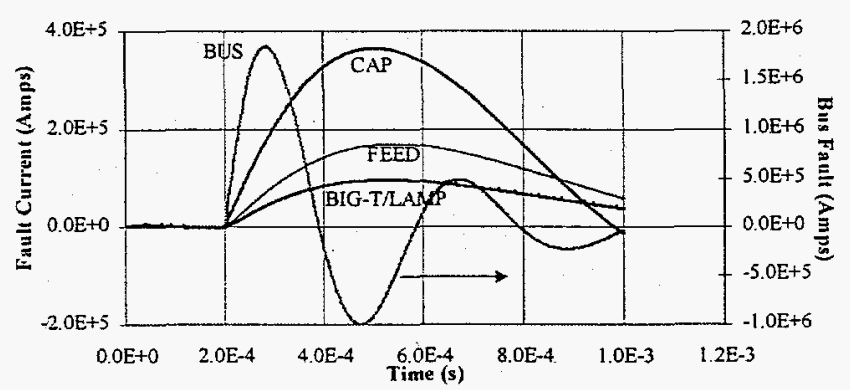

Figure 12. Overlay of possible fault-mode currents. 


\section{SUMMARY}

We have designed, modelled, fabricated, and tested the First Article NIF Test Module. We have and will continue evaluating it under normal and fault conditions to make final design refinements, if any are necessary. With our experience in developing this Power Conditioning System over its near lifetime-equivalent series of tests, we think it should meet NIF requirements for performance, cost, and compactness, with the flexibility to exceed some of the specifications.

\section{ACKNOWLEDGEMENTS}

The authors wish to express their appreciation to all the contributors on the PCS team. These include Doug Larson, Mark Newton, Steve Fulkerson, and Scot Hulsey at LLNL; Ed Weinbrecht, John Boyes, Dennis Muirhead, Dave VanDeValde, and Ellis Dawson at SNL; Bob Anderson of American Control Engineering; Bill Gagnon of LLNL. Our thanks are also due to the members of the FANTM operations crew, Gary Mowrer, Jacob Adcock, Bob Nichols, and Ray Gignac. All were responsible for the culmination of this project and paper.

\section{REFERENCES}

[1] M. L. Kiefer and M. M. Widner, "SCREAMER - A Pulsed Power Design Tool, User's Guide," in Digest of Tech. Papers, $5^{\text {th }}$ IEEE Pulsed Power Conf., eds. M. F. Rose and P. J. Turchi, 1985, p. 685.

[2] Private communications with Ken Jancaitis, LLNL. 